\title{
In Vivo Monitoring of Rat Spinal Cord Metabolism Using Hyperpolarized Carbon-13 MR Spectroscopic Imaging
}

\author{
(DI. Park, (D)S.J. Nelson, and (D).F. Talbott
}

\begin{abstract}
SUMMARY: This study demonstrated the feasibility of using hyperpolarized ${ }^{13} \mathrm{C}-\mathrm{MR}$ spectroscopic imaging with $\left[1{ }^{13} \mathrm{C}\right]$-pyruvate to evaluate in vivo spinal cord metabolism. High pyruvate and relatively small lactate signal were observed in the cervical spinal cords of naive rats. Lactate and pyruvate measures were similar for spinal cord and supratentorial brain. The results from this study establish baseline measures for spinal cord hyperpolarized MRS imaging with ${ }^{13} \mathrm{C}$ pyruvate. This technique holds promise as a valuable molecular imaging tool for monitoring biochemical processes in the normal and diseased spinal cord.
\end{abstract}

ABBREVIATION: MRSI $=$ MR spectroscopic imaging

$\mathbf{T}$

raumatic spinal cord injury is a devastating neurologic disorder affecting approximately 12,000 people in the United States each year. ${ }^{1}$ Secondary injury, which occurs hours to months after initial primary traumatic insult, contributes to metabolic stress and progressive tissue damage and serves as a prime target for therapeutic intervention. ${ }^{2}$ Current noninvasive methods to monitor these processes are significantly limited. ${ }^{1} \mathrm{H}$-MRS of spine suffers from low SNR, physiologic motion, and magnetic field inhomogeneity related to the bony spine. ${ }^{3}$

Dissolution dynamic nuclear polarization enables the acquisition of ${ }^{13} \mathrm{C} \mathrm{MR}$ data with a dramatic gain in sensitivity over conventional ${ }^{13} \mathrm{C}$ MR methods. ${ }^{4}$ Recent studies using the hyperpolarized substrate $\left[1-{ }^{13} \mathrm{C}\right]$-pyruvate have demonstrated the promise of this technique for examining in vivo metabolism in brain. ${ }^{5,6} \mathrm{~A}$ first-in-human study using hyperpolarized ${ }^{13} \mathrm{C}-\mathrm{MR}$ spectro-

Received June 3, 2016; accepted after revision July 6.

From the Department of Radiology and Biomedical Imaging (I.P., S.J.N., J.F.T.), Department of Bioengineering and Therapeutic Sciences (S.J.N.), and Brain and Spinal Injury Center (BASIC), San Francisco General Hospital (J.F.T.), University of California, San Francisco, San Francisco, California.

Dr. Ilwoo Park was supported by a National Cancer Institute training grant in translational brain tumor research (T32 CA151022). Support for the research studies came from National Institutes of Health grants R01EB013427, P41EB013598, and R21CA170148.

Paper previously presented in part at: Annual Meeting of the International Society of Magnetic Resonance in Medicine (ISMRM), May 30-31, 2015; Toronto, Ontario, Canada.

Please address correspondence to llwoo Park, PhD, Department of Radiology \& Biomedical Imaging, 1700 4th St, Box 2532, BH-303, University of California, San Francisco, San Francisco, CA 94158; e-mail: ilwoo.park@ucsf.edu

- Indicates open access to non-subscribers at www.ajnr.org

http://dx.doi.org/10.3174/ajnr.A4920 scopic imaging (MRSI) showed the safety and feasibility of this technology for evaluating real-time metabolism in humans. ${ }^{7}$

The purpose of this study was to explore the feasibility of using hyperpolarized ${ }^{13} \mathrm{C}$-MRSI with $\left[1-{ }^{13} \mathrm{C}\right]$-pyruvate for evaluating in vivo metabolism of the spinal cord in rodents and establish baseline spectroscopic measures in the spinal cord relative to brain.

\section{MATERIALS AND METHODS}

A total of 6 healthy male Sprague-Dawley rats (median weight, $320 \mathrm{~g}$ ) were included in this study. Animal studies were approved by the Institutional Animal Care and Use Committee.

Animals were scanned on a $3 \mathrm{~T}$ clinical MR imaging system (Discovery MR750; GE Healthcare, Milwaukee, Wisconsin) with $40 \mathrm{mT} / \mathrm{m}, 150 \mathrm{mT} / \mathrm{m} / \mathrm{ms}$ gradients, a multinuclear spectroscopy hardware package, and a custom-designed, dual-tuned volume radiofrequency coil with a quadrature ${ }^{13} \mathrm{C}$ channel and linear ${ }^{1} \mathrm{H}$ channel with a length of $9 \mathrm{~cm}$. During each imaging session, rats were placed prone on a heated pad positioned inside the radiofrequency coil and scanner. Cervical lordosis was straightened with padding under the ventral neck to minimize partial volume effects with nonspinal tissue when imaging in the axial plane (Fig 1A). The spine at $\mathrm{C} 4-\mathrm{C} 5$ was placed at the center of the radiofrequency coil so that both the spine at $\mathrm{C} 4-\mathrm{C} 5$ position and the supratentorial brain were located within the 7-cm effective region of the coil. Anesthesia was maintained with a constant delivery of isoflurane (approximately $1.5 \%$ ). Before each ${ }^{13} \mathrm{C}$ imaging session, highresolution T2WI was obtained in the axial plane by using an FSE sequence (TE, $60 \mathrm{~ms}$; TR, $4000 \mathrm{~ms}$; FOV , $8 \mathrm{~cm}$; matrix size, $256 \times$ 256; 2-mm section thickness; and NEX, 8). For each ${ }^{13} \mathrm{C}$ experiment, a mixture of $35 \mu \mathrm{L}$ of $\left[1-{ }^{13} \mathrm{C}\right]$-pyruvate, $15 \mathrm{mmol} / \mathrm{L}$ OX063 trityl radical (GE Healthcare), and $1.5 \mathrm{mmol} / \mathrm{L}$ Gd-DOTA was 

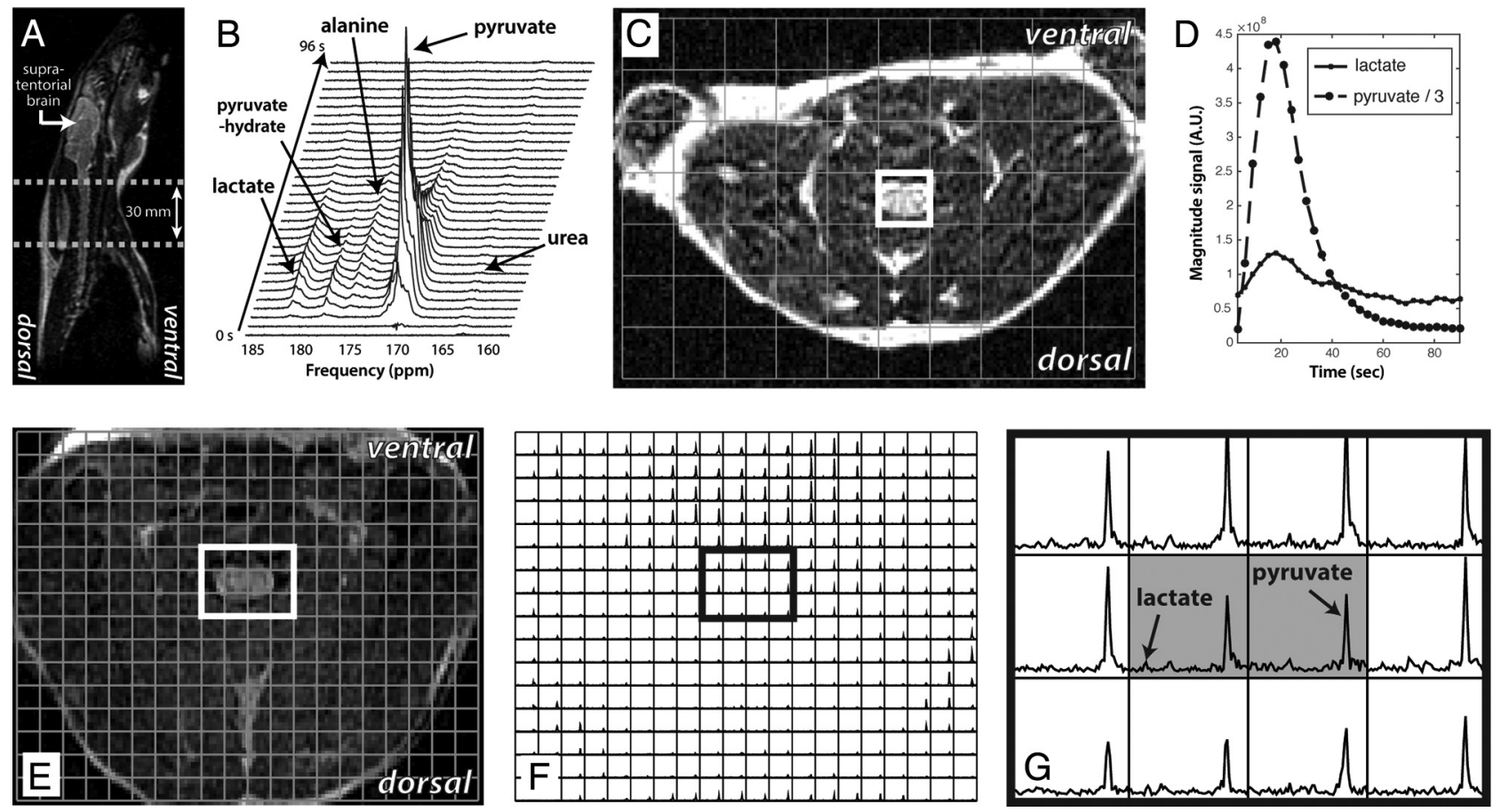

FIG 1. An example of hyperpolarized ${ }^{13} \mathrm{C}$ data from a naive rat. $A$, Horizontal dashed lines encompassing the neck delimit a 30-mm axial slab used for acquiring dynamic data in B. B, A stack plot of dynamic ${ }^{13} \mathrm{C}$ data from a $30-\mathrm{mm}$ slab. C, Axial T2WI of the neck centered at $\mathrm{C} 4 \mathrm{with}{ }^{13} \mathrm{C}$ spectral grid overlay for $2 \mathrm{D}$-localized ${ }^{13} \mathrm{C}$ dynamic data. $D$, Dynamic pyruvate and lactate signal change over time as measured from a $4.8 \times 4.8 \times 15 \mathrm{~mm}$ voxel primarily limited to the cervical spinal cord (white box, C). E, Axial T2WI with ${ }^{13} \mathrm{C}$ spectral grid overlay for $3 \mathrm{D}{ }^{13} \mathrm{C}-\mathrm{MRS}$ imaging. $F$, The corresponding ${ }^{13} \mathrm{C}$ spectra with high spatial resolution $(2 \times 2 \mathrm{~mm}$ in-plane voxel size) from a 5.4-mm axial section centered at the C4 vertebral level. G, Zoomed-in ${ }^{13} \mathrm{C}$ spectra targeting the spinal cord show high pyruvate and relatively small lactate signal in the spinal cord (highlighted voxels).

polarized by using a HyperSense polarizer (Oxford Instruments, Oxfordshire, United Kingdom) at $3.35 \mathrm{~T}$ and $1.4 \mathrm{~K}$ by irradiation with $94.1 \mathrm{GHz}$ microwaves by using methods described previously. ${ }^{4}$ After 60 minutes of microwave irradiation, the mixture was rapidly dissolved in a saline solution with $5.96 \mathrm{~g} / \mathrm{L}$ Tris (40 $\mathrm{mmol} / \mathrm{L}), 4.00 \mathrm{~g} / \mathrm{L} \mathrm{NaOH}(100 \mathrm{mmol} / \mathrm{L})$, and $0.1 \mathrm{mg} / \mathrm{L} \mathrm{Na}^{2}$ ethylenediaminetetraacetic acid. The final solution had a concentration of $100 \mathrm{mmol} / \mathrm{L}$ pyruvate and $\mathrm{pH} \sim 7.5$. A sample from the dissolved pyruvate solution with volume of $2.8 \mathrm{~mL}$ was injected into the tail vein of the rat over a 10 -second duration.

To determine an optimal temporal imaging window for acquiring 3D MRSI data, initial dynamic ${ }^{13} \mathrm{C}$ spectroscopic data were acquired from 2 rats. In 1 animal, section-localized data from a 30-mm axial slab encompassing the entire neck were acquired (Fig $1 A,-B$; TE, $35 \mathrm{~ms}$; TR, $3000 \mathrm{~ms}$; flip angle, $10^{\circ}$; 3 -second temporal resolution; and 32 total time points). To more specifically gauge temporal evolution of signal within spinal tissue of the neck, 2D-localized multivoxel data from a 15-mm axial section centered at the $\mathrm{C} 4$ vertebral level were acquired in a single animal (TE, $6.1 \mathrm{~ms}$; TR, $130 \mathrm{~ms}$; flip angle, $5^{\circ}$; 3 -second temporal resolution; 30 total time points; 10 phase encodes in the right-left direction; and a symmetric echo-planar readout in the anteroposterior direction providing $4.8 \times 4.8 \mathrm{~mm}$ in-plane resolution). ${ }^{8}$ Section-localized and multivoxel 2D-localized data were acquired from each animal simultaneous with the injection of pyruvate solution.

Compressed-sensing ${ }^{13} \mathrm{C} 3 \mathrm{D}$-MRSI data then were separately acquired from a total of 6 rats (including 2 rats described above) by using a double spin-echo sequence (TE, $140 \mathrm{~ms}$; TR, $215 \mathrm{~ms}$ ) with centric $k$-space encoding, a variable flip angle scheme, and flyback echo-planar readout on the $\mathrm{z}$-axis ${ }^{5}$ at 18 seconds from the start of the injection. Eighty-six phase encodes were collected from a $20 \times 16$ matrix in 18 seconds, resulting in $2 \times 2 \mathrm{~mm}$ in-plane resolution with 165.4 -mm sections.

The methods for processing ${ }^{13} \mathrm{C}$ data have been described previously. ${ }^{5-8}$ The SNR of lactate, pyruvate, and ratio of lactate over pyruvate were calculated from the ${ }^{13} \mathrm{C} 3 \mathrm{D}-\mathrm{MRSI}$ data by using the magnitude spectra. To estimate the SNR, the peak height for lactate and pyruvate were scaled by the standard deviation of the noise estimated from the spectrum that contained no metabolite resonances. The SNR of lactate, pyruvate, and ratio of lactate over pyruvate were estimated from voxels in the spine and compared with the corresponding values from voxels in supratentorial brain by using a 2 -tailed paired $t$ test.

\section{RESULTS}

Representative spectroscopic data are provided in Fig $1 .{ }^{13} \mathrm{C}$ spectra from the 30-mm axial section-localized acquisition encompassing the entire neck revealed $\left[1-{ }^{13} \mathrm{C}\right]$-pyruvate signal (171 $\mathrm{ppm}$ ) reaching its maximum amplitude at approximately $15 \mathrm{sec}-$ onds after the start of hyperpolarized pyruvate injection, followed by the maximum $\left[1-{ }^{13} \mathrm{C}\right]$-lactate signal $(183 \mathrm{ppm})$ at approximately 18 seconds (Fig $1 B$ ). After reaching its maximum, the pyruvate signal decreased rapidly, and the lactate signal decreased at a slower rate than pyruvate. Small $\left[1-{ }^{13} \mathrm{C}\right]$-alanine, pyruvate- 
Summary of ${ }^{13} \mathrm{C}$ metabolite quantification ${ }^{\mathrm{a}}$

\begin{tabular}{lccc}
\hline \multicolumn{1}{c}{ Location } & Pyruvate SNR & Lactate SNR & Lac/Pyr \\
\hline Normal spine $(n=6)$ & $32.1 \pm 7.5$ & $6.1 \pm 1.0$ & $0.23 \pm 0.05$ \\
$\begin{array}{l}\text { Supratentorial normal } \\
\text { brain }(n=6)\end{array}$ & $29.2 \pm 5.2$ & $6.0 \pm 0.8$ & $0.23 \pm 0.04$ \\
\hline
\end{tabular}

Note:- Lac/Pyr indicates the ratio of lactate to pyruvate.

${ }^{\text {a }}$ All values are mean \pm standard error.

hydrate, and urea peaks from an external reference also were observed.

Dynamic acquisition of pyruvate and lactate signal from a $4.8 \times 4.8 \times 15 \mathrm{~mm}$ voxel primarily encompassing the spinal cord (white box in Fig 1C) were plotted over time (Fig 1D). Both pyruvate and lactate signal reached maximum amplitude approximately 18 seconds after pyruvate injection, very similar to the temporal profile for ${ }^{13} \mathrm{C}$ spectra sampling the entire neck. This ${ }^{13} \mathrm{C}$ temporal profile closely matches results observed in the normal rat brain. ${ }^{5}$ The period of $18-35$ seconds after injection was therefore used as an imaging window for subsequent ${ }^{13} \mathrm{C} 3 \mathrm{D}$-MRSI studies.

${ }^{13} \mathrm{C} 3 \mathrm{D}-\mathrm{MRSI}$ reveals prominent pyruvate signal symmetrically within the ventrolateral soft tissues of the neck corresponding to the anatomic location of major neck vessels, consistent with blood pool signal (Fig $1 F$ ). The ${ }^{13} \mathrm{C}$ spectra corresponding to the spinal cord exhibited pyruvate peaks with excellent SNR and relatively small lactate peaks in the normal cord (highlighted voxels in Fig $1 G$ ). The SNR of pyruvate and lactate as well as ratio of lactate over pyruvate were compared between the spine and supratentorial brain in the Table. Ratio of lactate over pyruvate in the spine was $0.23 \pm 0.05$ (mean \pm standard error), which is similar to the respective value from supratentorial normal brain tissue $(P>.8)$.

\section{DISCUSSION}

We have demonstrated the feasibility of using hyperpolarized ${ }^{13} \mathrm{C}$ metabolic imaging for assessing in vivo metabolism in the cervical spine of rats. The use of hyperpolarized $\left[1-{ }^{13} \mathrm{C}\right]$-pyruvate provided sufficient signal to detect its transfer of the ${ }^{13} \mathrm{C}$ label to lactate in the spinal cord. High spatial resolution of ${ }^{13} \mathrm{C}$ spectra $(2 \times 2 \mathrm{~mm}$ in-plane voxel size) enabled the voxel segmentation of the cord into hemicords, which will enable the comparison of hemicontusion lesion with a contralateral hemicord. ${ }^{9}$

We believe that the molecular imaging technique presented in this paper will be most valuable in the setting of moderate spinal cord injuries, where prognosis is unclear based on clinical and conventional MR imaging sequences. ${ }^{10}$ In case of severe spinal cord trauma with the presence of significant hemorrhage, the susceptibility artifact due to blood products might pose a challenge in analyzing data acquired using hyperpolarized ${ }^{13} \mathrm{C}$ metabolic imaging.

The results from this study establish baseline pyruvate and lactate measures in the normal spinal cord and suggest that hyperpolarized ${ }^{13} \mathrm{C}$ pyruvate MRSI is a promising noninvasive tool for monitoring biochemical processes in the spinal cord.

Disclosures: Ilwoo Park—RELATED: Grant: National Institutes of Health,* Comments: National Institutes of Health grants R01EB013427, P41EB013598, and R21CA170148. National Cancer Institute, ${ }^{*}$ Comments: National Cancer Institute training grant in translational brain tumor research (T32 CA151022). Sarah J. NelsonUNRELATED: Grants/Grants Pending: GE Healthcare, ${ }^{*}$ Comments: academic-industry partnership related to imaging technology development. Jason TalbottUNRELATED: Consultancy: StemCells, Inc, Comments: data monitoring committee for clinical trial; now dissolved. *Money paid to the institution.

\section{REFERENCES}

1. Looby S, Flanders A. Spine trauma. Radiol Clin North Am 2011;49: 129-63 CrossRef Medline

2. Oyinbo CA. Secondary injury mechanisms in traumatic spinal cord injury: a nugget of this multiply cascade. Acta Neurobiol Exp (Wars) 2011;71:281-99 Medline

3. Stroman PW, Wheeler-Kingshott C, Bacon M, et al. The current state-of-the-art of spinal cord imaging: methods. Neuroimage 2014; 84:1070-81 CrossRef Medline

4. Ardenkjaer-Larsen JH, Fridlund B, Gram A, et al. Increase in signalto-noise ratio of $>\mathbf{1 0 , 0 0 0}$ times in liquid-state NMR. Proc Natl Acad Sci U S A 2003;100:10158-63 CrossRef Medline

5. Park I, Hu S, Bok R, et al. Evaluation of heterogeneous metabolic profile in an orthotopic human glioblastoma xenograft model using compressed sensing hyperpolarized 3D 13C magnetic resonance spectroscopic imaging. Magn Reson Med 2013;70:33-39 CrossRef Medline

6. Park I, Mukherjee J, Ito M, et al. Changes in pyruvate metabolism detected by magnetic resonance imaging are linked to DNA damage and serve as a sensor of temozolomide response in glioblastoma cells. Cancer Res 2014;74:7115-24 Medline

7. Nelson SJ, Kurhanewicz J, Vigneron DB, et al. Metabolic imaging of patients with prostate cancer using hyperpolarized $\left[1-{ }^{13} \mathrm{C}\right]$ pyruvate. Sci Transl Med 2013;5:198ra108 CrossRef Medline

8. Park I, Larson PE, Tropp JL, et al. Dynamic hyperpolarized carbon-13 MR metabolic imaging of nonhuman primate brain. Magn Reson Med 2014;71:19-25 CrossRef Medline

9. Gensel JC, Tovar CA, Hamers FP, et al. Behavioral and histological characterization of unilateral cervical spinal cord contusion injury in rats. J Neurotrauma 2006;23:36-54 CrossRef Medline

10. Bozzo A, Marcoux J, Radhakrishna M, et al. The role of magnetic resonance imaging in the management of acute spinal cord injury. J Neurotrauma 2011;28:1401-11 CrossRef Medline 